\title{
Study on the thermal cycle of Wire Arc Additive Manufactured (WAAM) carbon steel wall using numerical simulation
}

\author{
Mohsen Saadatmand, Reza Talemi \\ Department of Material Engineering, KU Leuven, Belgium \\ mohsen.saadatmand@kuleuven.be,reza.hoijatitalemi@kuleuven.be
}

ABSTRACT. The thermal behavior in WAAM process is a significant cause for thermal stress. In this paper, a 3D model of a four-layer wall is built in ABAQUS software in order to investigate the thermal behavior in a carbon steel (ASTM A36) WAAM wall. Moreover, the effects of substrate preheating temperature and travel speed on the temperature distribution are studied. The modelling results show that with increase in number of deposited layers, the peak temperature increases but average cooling speed decreases. Furthermore, substrate preheating increases peak temperature of fist layer and decreases its average cooling speed. Regarding simulation results, the travel speed has major effects on the thermal behavior of deposited layers.

KEYWORDS. Additive Manufacturing; Wire arc additive manufacturing; Finite element method; Low carbon steel.

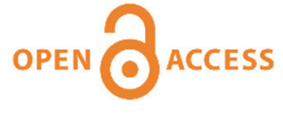

Citation: Saadatmand, M., Talemi, R., Study on the thermal cycle of Wire Arc Additive Manufactured (WAAM) carbon steel wall using numerical simulation, Frattura ed Integrità Strutturale, 52 (2020) 98-104.

Received: 24.10 .2020

Accepted: 19.12 .2019

Published: 01.04.2020

Copyright: (C) 2020 This is an open access article under the terms of the CC-BY 4.0, which permits unrestricted use, distribution, and reproduction in any medium, provided the original author and source are credited.

\section{INTRODUCTION}

A dditive manufacturing (AM) processes have become very noteworthy in recent years. They have many advantages in comparison to conventional processes [1]. The production of complex and individual components is possible with additive manufacturing processes.

Wire Arc Additive Manufacturing (WAAM) is a Directed Energy Deposition (DED) method, which uses an electric arc for melting the metallic materials [2]. The arc-based heat sources have recently attracted a lot of attention since they have proven the ability to produce large metallic structures [3]. The hardware cost for the WAAM system is typically an order of magnitude less than the laser powder systems and it can achieve deposition rates two orders of magnitude higher than laser powder systems (typically 2-4 kg/hour) [4]. Moreover, the WAAM process, in combination with a robot, also allows the production of complex geometries [5]. However, repeated heating and cooling cycles make a very large temperature gradient between the substrate and deposited layers, causing serious thermal stress, cracks, and even fracture of fabricated parts [6]. In order to manufacture a high-quality product, it is important to determine the interaction of each process parameter with the component properties. It is highly important to understand and control the temperature gradient and thermal stress for process optimization. According to Thompson et al. [7], the mechanical properties of the fabricated part are directly influenced by the microstructure, which drastically depends on the thermal history. As reported by Colegrove et al. [8], it is 
of great importance to have the process parameters and cooling rate under control and learn how they influence the properties of the material.

Besides experimental methods, numerical simulation has been demonstrated to be an efficient approach to study the thermal-mechanical behavior in additive manufacturing processes. Zhao et al. [9] obtained a 3D heat transfer model with temperature dependent material properties for studying the thermal cycling effects. They concluded that the heat diffusion conditions deteriorate by the increase in the deposition height. Xiong et al. [10] defined an Finite Element (FE) simulation for prediction of the heat dissipation mechanism in a tube of welds made using Gas Metal Arc (GMA)-WAAM. They demonstrated that the heat transport conditions in each layer are closely associated with the direction of deposition in the former layer.

The substrate preheating is one of the most effective methods to mitigate the thermal stress and crack. Therefore, it is important to explore the preheating impact on thermal behavior of WAAM parts. However, little has been done to model the effect of substrate preheating on thermal behavior in WAAM process [6]. Xiong et al. [6] used a H08Mn2S wire electrode and the commercial software MSC Marc was used for modelling of the WAAM process of a circular thin walled part.

In this study, a 3D finite element model is developed in ABAQUS software to study the thermal behavior of low carbon steel WAAM wall (ASTM A36). The temperature distribution in the middle point of deposited layer is studied and effects of substrate preheating temperature and travel speed are discussed.

\section{SIMULATION PROCEDURE}

In this section by using ABAQUS 2019 software, a 3D thermal elastic-plastic FE computational procedure was employed to simulate the temperature distribution in the WAAM wall of low carbon steel (ASTM A36) (WWLS). The temperaturedependent thermal-mechanical properties of ASTM A36 were obtained from the literature [11] (Tab. 1). The substrate and deposited material are assumed to have the identical material properties and to be isotropic.

\begin{tabular}{cccccccc}
\hline $\begin{array}{c}\text { Temperature } \\
\left({ }^{\circ} \mathrm{C}\right)\end{array}$ & $\begin{array}{c}\text { Specific heat } \\
\left(\mathrm{J} / \mathrm{kg}^{\circ} \mathrm{C}\right)\end{array}$ & $\begin{array}{c}\text { Thermal } \\
\text { conductivity } \\
\left(\mathrm{W} / \mathrm{m}^{\circ} \mathrm{C}\right)\end{array}$ & $\begin{array}{c}\text { Density } \\
\left(\mathrm{Kgm}^{-3}\right)\end{array}$ & $\begin{array}{c}\text { Yield stress } \\
(\mathrm{MPa})\end{array}$ & $\begin{array}{c}\text { Thermal } \\
\text { expansion } \\
\text { coefficient } \\
\left(10^{-5} /{ }^{\circ} \mathrm{C}\right)\end{array}$ & $\begin{array}{c}\text { Young } \\
\text { Modulus } \\
(\mathrm{GPa})\end{array}$ & $\begin{array}{c}\text { Poisson's } \\
\text { ratio }\end{array}$ \\
\hline 0 & 400 & 60 & 7880 & 250 & 1.15 & 210 & 0.3 \\
100 & 500 & 50 & 7880 & 240 & 1.2 & 200 & 0.3 \\
200 & 520 & 45 & 7800 & 230 & 1.42 & 200 & 0.3 \\
400 & 650 & 38 & 7760 & 200 & 1.45 & 170 & 0.3 \\
600 & 750 & 30 & 7600 & 180 & 1.45 & 80 & 0.3 \\
800 & 1000 & 25 & 7520 & 150 & 1.45 & 35 & 0.3 \\
1000 & 1200 & 26 & 7390 & 125 & 1.45 & 20 & 0.3 \\
1200 & 1400 & 28 & 7300 & 80 & 1.45 & 15 & 0.3 \\
1400 & 1600 & 37 & 7250 & 35 & 1.45 & 10 & 0.3 \\
1550 & 1700 & 37 & 7180 & 30 & 1.45 & 10 & 0.3 \\
\hline
\end{tabular}

Table 1: The temperature-dependent thermal-physical properties of low carbon steel ASTM A36 [11]

The model was developed for the WWLS, containing 4 layers with a layer height of $2.5 \mathrm{~mm}$. The 3D finite element mesh model is shown in Fig. 1. A symmetry plane was used to save computational time in the model of the WWLS without sacrificing the physics of the process. The model was meshed with the eight-noded, three-dimensional brick element type. The mesh size for deposited layers was $1.25 \mathrm{~mm}$ along the thickness of deposited layers and increased gradually away from the deposited layers. 


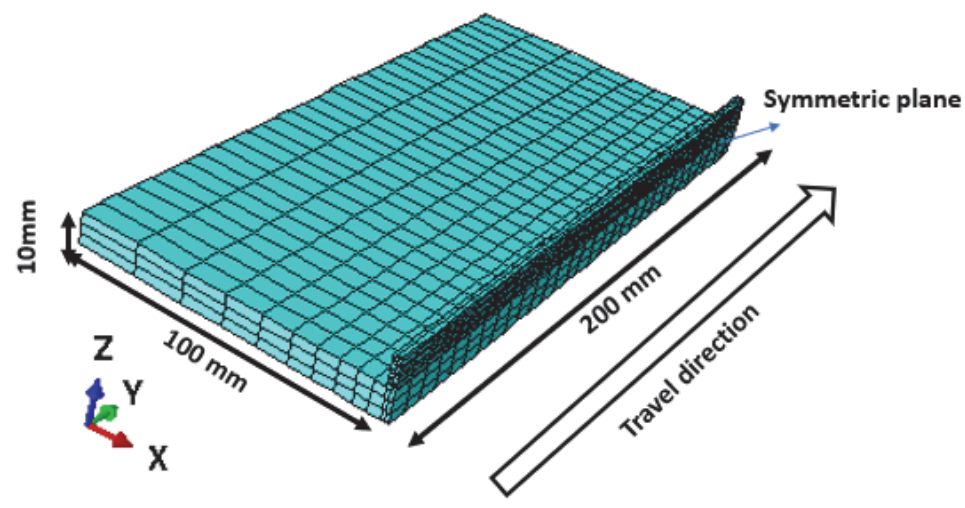

Figure 1: Finite element mesh for the WWLS

The arc continuously moved along y direction (travel direction indicated in Fig. 1) with no interlayer idle time (IIT). A code written as subroutine (DFLUX) in the FORTRAN programming language was used in order to apply a moving volumetric heat source for modelling of arc, based on the double ellipsoidal distribution proposed by Goldak [12], which is expressed by the following equations. For the front heat source [12]:

$$
q_{f}=\frac{6 \sqrt{3} f_{f} Q^{-3}}{a b c_{f} \sqrt{\pi}} e^{-3\left(\frac{x^{2}}{a^{2}}+\frac{y^{2}}{b_{f}^{2}}+\frac{z^{2}}{c^{2}}\right)}
$$

And for the rear heat source [12]:

$$
q_{f}=\frac{6 \sqrt{3} f_{r} Q}{a b c_{r} \sqrt{\pi}} e^{-3\left(\frac{x^{2}}{a^{2}}+\frac{y^{2}}{b_{r}^{2}}+\frac{z^{2}}{c^{2}}\right)}
$$

where $\mathrm{Q}$ is the heat source power, $\mathrm{x}, \mathrm{y}$ and $\mathrm{z}$ are the local coordinates of the double ellipsoid model aligned with the deposition line. The parameters $\mathrm{a}, \mathrm{b}_{\mathrm{r}}, \mathrm{b}_{\mathrm{f}}$ and $\mathrm{c}$ are associated to the features of heat source, as indicated in Fig. 2(a). These parameters were determined from results reported by Nuraini et al. [13] (Tab. 2).

\begin{tabular}{cc}
\hline Parameter & Value \\
Length of front ellipsoidal $\left(\mathrm{b}_{\mathrm{f}}\right)(\mathrm{mm})$ & 10.1 \\
Length of rear ellipsoidal $(\mathrm{br})(\mathrm{mm})$ & 12.4 \\
Depth of the heat source $(\mathrm{c})(\mathrm{mm})$ & 6 \\
Half width of the heat source $(\mathrm{a})(\mathrm{mm})$ & 5 \\
Front heat fraction & 0.4 \\
Rear heat fraction & 1.6 \\
Energy input rate $(\mathrm{W})$ & 4752 \\
\hline
\end{tabular}

Table 2: The values for heat source parameters [13]

The heat source model considers the heat flux losses by convection and radiation; thus, during the FE analysis, a convection heat transfer coefficient of $35 \mathrm{~W} / \mathrm{m}^{2} \mathrm{~K}$, the radiative emissivity of 0.5 , and the Stefan-Boltzmann constant of $5.67 \times 10^{-8} \mathrm{~W}$ $\mathrm{m}^{-2} \mathrm{~K}^{-4}$ were used for the external sides of the substrate and layers [14]. The parameters for heat loss were not applied to the longitudinal mid-plane because of the symmetry thermal boundary. The latent heat was considered as $250 \mathrm{~kJ} / \mathrm{kg}$ between the solidus temperature $1460^{\circ} \mathrm{C}$ and the liquidus temperature $1520^{\circ} \mathrm{C}$ [15]. To simulate material deposition and mimic the additive nature of the WAAM process, the element birth technique method was used. With the model change option in ABAQUS, all the elements of the deposited layers are deactivated at the initial step of the analysis, and then the elements of each layer are activated, simulating material deposition layer by layer stacked to each other. The initial temperature of the substrate and deposited layers were considered as $25^{\circ} \mathrm{C}$. 
In this study, the numerical temperature cycle at four distinct locations was computed during the WAAM process. Fig. 2(b) represents the location of middle points of the first, second, third and fourth layer, namely, p1, p2, p3 and p4, respectively. To investigate effects of substrate preheating, the substrate was preheated at $200^{\circ} \mathrm{C}, 400^{\circ} \mathrm{C}$ and $600^{\circ} \mathrm{C}$. Also, travel speeds of $10 \mathrm{~mm} / \mathrm{s}, 12,5 \mathrm{~mm} / \mathrm{s}$ and $15 \mathrm{~mm} / \mathrm{s}$ were considered in order to investigate effects of travel speed on the thermal behavior of deposited layers.

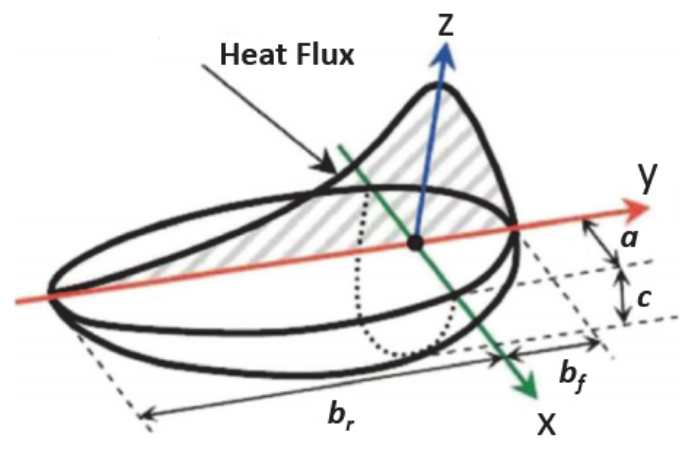

(a)

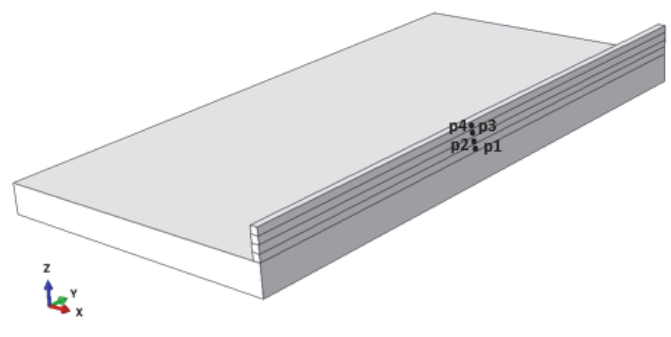

(b)

Figure 2: (a) Schematic diagram of Goldak model [16], (b) the location of middle points of the first, second, third and fourth layer, namely, p1, p2, p3 and p4, respectively.

\section{RESULTS \& DISCUSSION}

\section{Thermal cycles during $W A A M$ process}

$\mathrm{F}$ ig. 3 illustrates the thermal cycles of middle point of the four layers (deposited with the travel speed of $12.5 \mathrm{~mm} / \mathrm{s}$ ), namely, p1, p2, p3 and p4, as is showed in Fig. 2. As indicated in Fig 3, in the middle point of the first layer, the temperature increases sharply to the peak when the heat source approached. When the heat source travelled to the middle point of the second layer, the temperature of the middle point of first layer also increases. During the deposition of second layer, because of the preheating of the previous deposition (first layer), the peak temperature of the second layer increases to a higher value compared to that of first deposited layer (indicated by dashed line). Also, the increase rate for reheating peak temperature seems to be slightly higher compared to that for first peak temperature. It can be attributed to this fact that for previously deposited layers the heat cannot escape so more increase in temperature is expected.

As shown in Fig. 3, every thermal cycling curve has two continues peaks exceeding the melting point, resulting in enough condition for metallurgy bonding. The peak temperatures of the middle point of first layer is lower due to the influence of the initial temperature of substrate. Since the initial temperature of the substrate is lower (room temperature, $25^{\circ} \mathrm{C}$ ), which makes the heat dissipation quickly, the average cooling speed for first layer is higher compared to that of subsequent deposited layers. The average cooling speed for first layer is about $123{ }^{\circ} \mathrm{C} / \mathrm{s}$ which drops to $115{ }^{\circ} \mathrm{C} / \mathrm{s}$ for the third layer. Here, it should be noted that by increasing the number of deposited layers, the peak temperature will increase from $2518^{\circ} \mathrm{C}$ for the first layer to $2640^{\circ} \mathrm{C}$ for fourth deposited layer. For a substrate at room temperature, a large temperature gradient between the substrate and deposited layers causes serious thermal stress, cracking and even fracture of fabricated parts, as reported in the literature [6]. To mitigate the thermal stress and cracks, substrate preheating is one of the most effective methods. In the next part, the effects of substrate preheating temperature on the thermal behavior of deposited layers are investigated.

\section{Effect of substrate preheating on the thermal cycle of deposited layers}

Fig. 4 provides the thermal cycle of the middle point in the first layer for non-preheated and preheated substrate with temperature of $200{ }^{\circ} \mathrm{C}, 400{ }^{\circ} \mathrm{C}$ and $600{ }^{\circ} \mathrm{C}$. The first peak temperature value varies from $2518{ }^{\circ} \mathrm{C}$ to $2537{ }^{\circ} \mathrm{C}, 2567{ }^{\circ} \mathrm{C}$ and $2600{ }^{\circ} \mathrm{C}$ with the increase of the preheating temperature from non-preheated to $200{ }^{\circ} \mathrm{C}, 400{ }^{\circ} \mathrm{C}$ and $600{ }^{\circ} \mathrm{C}$, respectively. Also, with increase in preheating temperature to $600^{\circ} \mathrm{C}$, the average cooling speed decreases gradually to $118^{\circ} \mathrm{C} / \mathrm{s}$. This can be explained by the fact that when the preheating temperature increases, the temperature difference between the substrate and the first layer decreases, resulting in a bad heat conduction condition of the deposited layer [17]. 


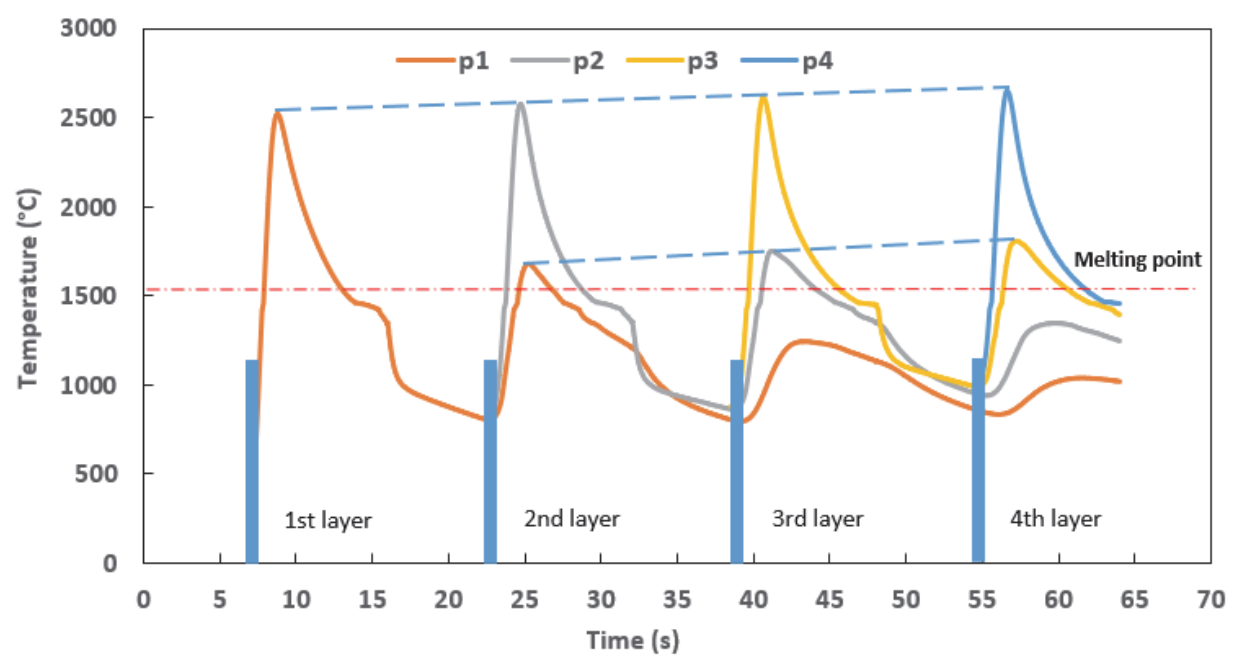

Figure 3: Computed thermal cycles of p1, p2, p3 and p4 with the travel speed of $12.5 \mathrm{~mm} / \mathrm{s}$.

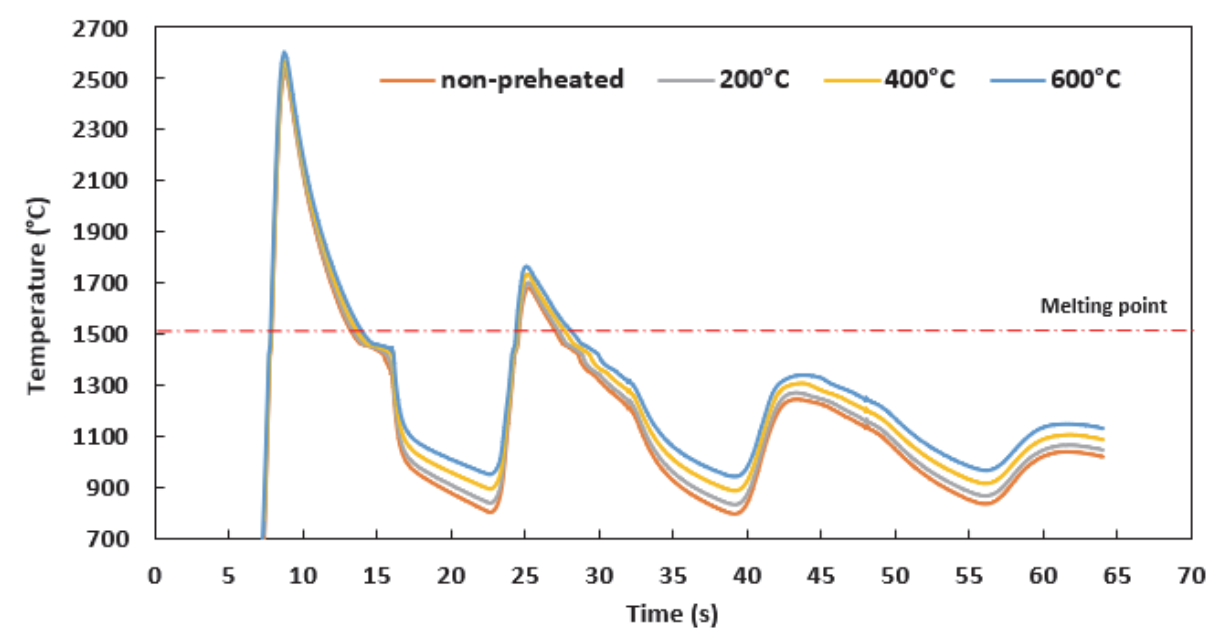

Figure 4: Thermal cycle of the middle point in the first layer for non-preheated and preheated substrate with temperature of $200{ }^{\circ} \mathrm{C}$, 400 ${ }^{\circ} \mathrm{C}$ and $600{ }^{\circ} \mathrm{C}$.

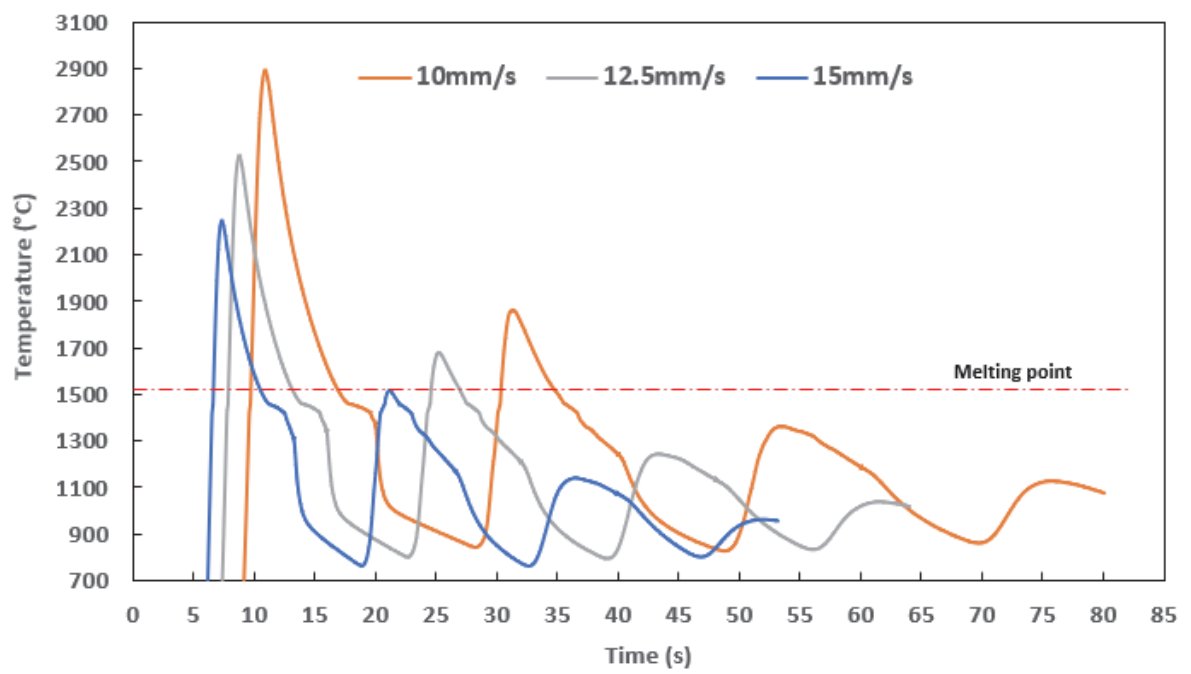

Figure 5: The peak temperature of middle point in the first layer for travel speed of $10,12.5$ and $15 \mathrm{~mm} / \mathrm{s}$ 
Effect of travel speed on thermal cycle of deposited layers

The temperature distributions of $\mathrm{p} 1$ with different travel speeds are shown in Fig. 5. As shown in Fig 5, with increasing the travel speed, the maximum temperature for each point decreases. The reason is that as the travel speed reduces, the interaction time between arc and material increases. As a result, more energy transfers to the material, therefore temperature increases. Also, with increase in travel speed from 10 to $15 \mathrm{~mm} / \mathrm{s}$, the average cooling speed increases from $118^{\circ} \mathrm{C} / \mathrm{s}$ to $136^{\circ} \mathrm{C} / \mathrm{s}$ for the middle point in the first layer. Moreover, for the travel speed of $15 \mathrm{~mm} / \mathrm{s}$, the second peak is approaching the melting point, so it influences the metallurgy bonding between deposited layers.

\section{CONCLUSIONS}

I $\mathrm{n}$ this work, a 3D finite element model has been developed to study the thermal cycle during the WAAM process along with the effects of substrate preheating temperature and travel speed on the thermal cycle of WAAM manufactured wall of low carbon steel (ASTM A36). It has been found that, during the WAAM process, the peak temperature of newly deposited layers increases (from $2518^{\circ} \mathrm{C}$ to $2640^{\circ} \mathrm{C}$ ) but the average cooling speed decreases (from $123^{\circ} \mathrm{C} / \mathrm{s}$ to 115 ${ }^{\circ} \mathrm{C} / \mathrm{s}$ ) due to the influence of previously deposited layers. Moreover, with the increase of substrate's preheating temperature, the peak temperature of first layer increases (from $2518^{\circ} \mathrm{C}$ to $2600^{\circ} \mathrm{C}$ ). In addition, the cooling rate of first layer decreases gradually from $123^{\circ} \mathrm{C} / \mathrm{s}$ to $118^{\circ} \mathrm{C} / \mathrm{s}$ with the increasing preheating temperature. Furthermore, from the obtained numerical results it can be concluded that the travel speed has a major impact on the thermal behavior and metallurgical bonding of deposited layers.

\section{REFERENCES}

[1] Wu, B., Pan, Z., Ding, D., Cuiuri, D., Li, H., Xu, J., Norrish, J. (2018). A review of the wire arc additive manufacturing of metals: properties, defects and quality improvement, J. Manuf. Process., 35(February), pp. 127-139, DOI: 10.1016/j.jmapro.2018.08.001.

[2] Haden, C. V., Zeng, G., Carter, F.M., Ruhl, C., Krick, B.A., Harlow, D.G. (2017). Wire and arc additive manufactured steel: Tensile and wear properties, Addit. Manuf., 16(2010), pp. 115-123, DOI: 10.1016/j.addma.2017.05.010.

[3] Hejripour, F., Binesh, F., Hebel, M., Aidun, D.K. (2019). Thermal modeling and characterization of wire arc additive manufactured duplex stainless steel, J. Mater. Process. Technol., 272(March), pp. 58-71, DOI: 10.1016/j.jmatprotec.2019.05.003.

[4] Ding, J. (2012).Thermo-mechanical Analysis of Wire and Arc Additive Manufacturing Process. Cranfield University.

[5] Kazanas, P., Deherkar, P., Almeida, P., Lockett, H., Williams, S. (2012). Fabrication of geometrical features using wire and arc additive manufacture, Proc. Inst. Mech. Eng. Part B J. Eng. Manuf., 226(6), pp. 1042-1051, DOI: $10.1177 / 0954405412437126$.

[6] Xiong, J., Lei, Y., Li, R. (2017). Finite element analysis and experimental validation of thermal behavior for thin-walled parts in GMAW-based additive manufacturing with various substrate preheating temperatures, Appl. Therm. Eng., 126, pp. 43-52, DOI: 10.1016/j.applthermaleng.2017.07.168.

[7] Thompson, S.M., Bian, L., Shamsaei, N., Yadollahi, A. (2015). An overview of Direct Laser Deposition for additive manufacturing; Part I: Transport phenomena, modeling and diagnostics, Addit. Manuf., 8, pp. 36-62, DOI: $10.1016 /$ j.addma.2015.07.001.

[8] Colegrove, P.A., Coules, H.E., Fairman, J., Martina, F., Kashoob, T., Mamash, H., Cozzolino, L.D. (2013). Microstructure and residual stress improvement in wire and arc additively manufactured parts through high-pressure rolling, J. Mater. Process. Technol., 213(10), pp. 1782-1791, DOI: 10.1016/j.jmatprotec.2013.04.012.

[9] Zhao, H., Zhang, G., Yin, Z., Wu, L. (2011). A 3D dynamic analysis of thermal behavior during single-pass multi-layer weld-based rapid prototyping, J. Mater. Process. Technol., 211(3), pp. 488-495, DOI: $10.1016 /$ j.jmatprotec.2010.11.002.

[10] Xiong, J., Li, R., Lei, Y., Chen, H. (2018). Heat propagation of circular thin-walled parts fabricated in additive manufacturing using gas metal arc welding, J. Mater. Process. Technol., 251, pp. 12-19, DOI: 10.1016/j.jmatprotec.2017.08.007.

[11] Stamenkovic, D., Vasovic, I. (2009). Finite Element Analysis of Residual Stress in Butt Welding Two Similar Plates, Sci. Tech. Rev., LIX(1), pp. 57-60.

[12] Goldak, J., Chakravarti, A., Bibby, M. (1984). A new finite element model for welding heat sources, Metall. Trans. B, 
15(2), pp. 299-305, DOI: 10.1007/BF02667333.

[13] Nuraini, A., Zainal, A., AzmahHanim, M. (2013). The Effect of Welding Process Parameter on Temperature and Residual Stress in Butt- Joint Weld of Robotic Gas Metal Arc Welding, Aust. J. Basic Appl. Sci., 7(7), pp. 814-820.

[14] Graf, M., Hälsig, A., Höfer, K., Awiszus, B., Mayr, P. (2018). Thermo-mechanical modelling of wire-arc additive manufacturing (WAAM) of semi-finished products, Metals (Basel)., 8(12), DOI: 10.3390/met8121009.

[15] Eisazadeh, H., Achuthan, A., Goldak, J.A., Aidun, D.K. (2015). Effect of material properties and mechanical tensioning load on residual stress formation in GTA 304-A36 dissimilar weld, J. Mater. Process. Technol., 222(August), pp. 344 355, DOI: 10.1016/j.jmatprotec.2015.03.021.

[16] Nezamdost, M.R., Esfahani, M.R.N., Hashemi, S.H., Mirbozorgi, S.A. (2016). Investigation of temperature and residual stresses field of submerged arc welding by finite element method and experiments, Int. J. Adv. Manuf. Technol., 87(14), pp. 615-624, DOI: 10.1007/s00170-016-8509-4.

[17] Hu, Z., Qin, X., Shao, T. (2017).Welding Thermal Simulation and Metallurgical Characteristics Analysis in WAAM for 5CrNiMo Hot Forging Die Remanufacturing. Procedia Engineering, 207, pp. 2203-8. 